\title{
Efeitos da Energia de Soldagem e Consumível sobre a Resistência à Flexão Simples de Juntas Soldadas em Perfis Tubulares de Aço TMCP
}

\author{
Rafael Luciano Dalcin¹, Ivan Guerra Machado ${ }^{1}$, Arnaldo Ruben Gonzalez ${ }^{1}$, José Antônio Esmerio Mazzaferro \\ 1 Universidade Federal do Rio Grande do Sul - UFRGS, Laboratório de Soldagem \& Técnicas Conexas, Porto Alegre, RS, Brasil.
}

Recebido: 08 Dez., 2015

Aceito: 07 Mar., 2016

E-mails: rafaellucianodalcin@hotmail. com (RLD), welder@ufrgs.br (IGM), ruben@mecanica.ufrgs.br (ARG), mazza@ufrgs.br (JAEM)
Resumo: A introdução dos aços fabricados por processamento termomecânico controlado (TMCP) demandou maiores propriedades mecânicas e metalúrgicas das juntas soldadas sobre eles produzidas. Em função desses fatores, a energia de soldagem é estritamente limitada, e para evitar uma eventual redução da resistência mecânica da zona afetada pelo calor (ZAC), é necessário testar os procedimentos de soldagem próximos daqueles que serão usados na estrutura real. Desta forma, o objetivo deste estudo é obter dados detalhados referentes à eficiência mecânica de juntas soldadas pelo processo MAG e com diferentes energias de soldagem, sobre perfis tubulares quadrados em aço TMCP, formando um conjunto soldado coluna/viga. Portanto, seis distintas energias de soldagem e dois metais de adição foram utilizados (AWS ER80S-G e AWS ER120S-G), com as soldas posicionadas em todo o contorno do perfil. As doze estruturas soldadas foram instrumentadas e submetidas à flexão simples. Comparando-se as juntas soldadas produzidas com mesma energia de soldagem, e apesar dos efeitos similares sobre a zona afetada pelo calor (ZAC), aquelas fabricadas com o consumível AWS ER120S-G apresentaram maior resistência mecânica.

Palavras-chave: Soldagem MAG; Aço TMCP; Energia de soldagem; Perfil tubular; Resistência mecânica da junta soldada; Flexão simples.

\section{Effects of Heat Input and Consumable on Simple Bending Strength of Welded Joints in TMCP Steel Tubular Profiles}

\begin{abstract}
The introduction of steels made by thermomechanical controlled processing (TMCP) demanded higher mechanical and metallurgical properties of the welded joints produced on them. Given these factors, the heat input is strictly limited, and to avoid any reduction in the mechanical strength of the heat affected zone (HAZ), it is required to test welding procedures close to those that will be used in the actual structure. Therefore, the aim of this study is to obtain detailed data on the mechanical efficiency of welded joints by GMAW process and different heat inputs, on square tubular profiles in TMCP steel, disposed as a column/beam weldment. So, six different heat inputs and two filler metals were used (AWS ER80S-G and AWS ER120S-G), with welds located around the profile contour. The twelve welded structures were instrumented and subjected to simple bending. Comparing welded joints produced with same heat input, and despite similar effects on the heat affected zone (HAZ), those made with consumable AWS ER120S-G have shown higher mechanical strength.
\end{abstract}

Key-words: GMAW; TMCP steel; Heat input; Tubular profile; Welded joint Mechanical strength; Simple bending.

\section{Introdução}

O processamento termomecânico controlado (TMCP) envolve o controle rigoroso da austenita durante a laminação a quente, de modo que os seus grãos se transformem em ferrita refinada ao final desta etapa. O conceito básico do TMCP é garantir e melhorar as propriedades mecânicas através do controle das mudanças microestruturais durante o processo de deformação a quente [1]. Para uma dada composição química, as propriedades mecânicas finais dependerão da taxa de resfriamento e da sequência de laminação. Para retardar, ou suprimir a recristalização da austenita deformada, são geralmente utilizados elementos químicos tais como boro, nióbio, titânio ou vanádio, usualmente em proporções variando entre 0,001\% e alguns décimos por cento. Deste modo, além das bandas de deformação no seu interior, são produzidos grãos muito alongados de austenita,
Este é um artigo publicado em acesso aberto (Open Access) sob a licença Creative Commons Attribution Non-Commercial, que permite uso, distribuição e reproduçãa em qualquer meio, sem restrições des de que sem fins comerciais e que 0 trabalho original seja corretamente citado. 
Efeitos da Energia de Soldagem e Consumível sobre a Resistência à Flexão Simples de Juntas Soldadas em Perfis Tubulares de Aço TMCP

com grande área nos seus contornos, que agem como sítios de nucleação para fases com grãos extremamente pequenos [2].

Neste contexto, o desenvolvimento dos aços TMCP tem sido voltado para otimizar o efeito do refino de grão sobre o aumento da resistência e da tenacidade dos aços [2-4]. Assim, a busca pela redução do teor de carbono e o aumento dos teores de manganês em aços processados por laminação controlada, levaram ao desenvolvimento de aços endurecidos por transformação de fase. Estes aços apresentam tensão de escoamento contínua e grande aumento na resistência a tração quando comparados aos aços convencionais (ferrita + perlita) [2,5].

Dentre os aços desse tipo disponíveis comercialmente enquadra-se o DOMEX 700 MC ${ }^{\text {тM }}$, laminado a quente e que segundo seus fabricantes [6] satisfaz ou ultrapassa o requerido pela EN 10149-2 [7]. Estes aços são geralmente empregados em aplicações tais como guindastes, equipamentos para terraplanagem, implementos rodoviários e agrícolas, inclusive carrocerias de ônibus e na indústria automotiva. As elevadas propriedades mecânicas destes aços permitem a sua utilização em menor espessura, proporcionando a (quase sempre) desejada redução de peso das estruturas [6].

Durante a soldagem dos aços DOMEX $700 \mathrm{MC}^{\mathrm{TM}}$ são formadas na ZAC regiões de baixa dureza devido às alterações da microestrutura (decorrentes das temperaturas e tempos que a junta soldada fica exposta), além disso, a dureza e a microestrutura podem ser afetadas pela composição química do metal base (MB) e do metal de solda (MS). Contudo, a largura da ZAC irá aumentar e a dureza irá cair quando a soldagem for realizada com energias de soldagem mais elevadas; portanto estes fatores devem ser controlados durante a soldagem [8-11]. Quando submetidas a carregamento, as juntas soldadas usualmente fraturam nas regiões de menor dureza da ZAC, pois nelas a resistência mecânica será inferior ao MB. Para garantir que as propriedades mecânicas não sejam comprometidas nas juntas soldadas sobre estes aços, é recomendado o uso de energia de soldagem relativamente baixa, ou seja, menor do que aproximadamente $1 \mathrm{~kJ} / \mathrm{mm}[6]$.

Portanto, o objetivo maior deste trabalho é verificar os efeitos da energia de soldagem sobre possíveis quedas de resistência na ZAC, e avaliar a influência do metal de adição na resistência mecânica de juntas soldadas sobre aços DOMEX $700 \mathrm{MC}^{\mathrm{TM}}$ submetidos à flexão simples.

\section{Materiais e Métodos}

\subsection{Metal base}

Perfis tubulares quadrados com costura (soldados longitudinalmente) em aço DOMEX $700 \mathrm{MC}^{\text {TM }}$, com dimensões $100 \mathrm{~mm} \times 100 \mathrm{~mm}$ e $3 \mathrm{~mm}$ de espessura de parede, foram utilizados como MB. O método utilizado para análise química do MB foi espectrometria de emissão óptica, através do equipamento Spectro Lab. As propriedades mecânicas do MB foram medidas em quatro amostras na direção de laminação, entretanto, as amostras foram confeccionadas conforme recomendações da NBR ISO 6892 [12]. O percentual de elementos químicos e propriedades mecânicas medidas são mostrados na Tabela 1.

Tabela 1. Composição química e propriedades mecânicas medidas do metal base.

\begin{tabular}{|c|c|c|c|c|c|c|c|c|}
\hline \multicolumn{9}{|c|}{ Elemento Químico (\% em massa) } \\
\hline C & Si & Mn & $\mathbf{P}$ & $\mathbf{S}$ & $\mathrm{Cr}$ & Mo & $\mathbf{N i}$ & Al \\
\hline 0,0678 & 0,0468 & 1,98 & 0,006 & $<0,00100$ & 0,041 & $<0,005$ & 0,0289 & 0,0292 \\
\hline Co & $\mathrm{Cu}$ & Nb & $\mathrm{Ti}$ & $\mathbf{V}$ & $\mathbf{w}$ & $\mathbf{P b}$ & Sn & B \\
\hline 0,0163 & $<0,0100$ & 0,0555 & 0,106 & 0,0164 & $<0,0100$ & $<0,00200$ & $<0,00100$ & $<0,00010$ \\
\hline \multicolumn{9}{|c|}{ Propriedades Mecânicas (valores médios) } \\
\hline \multicolumn{3}{|c|}{ Tensão de escoamento } & \multicolumn{3}{|c|}{ Limite de resistência à tração } & \multicolumn{3}{|c|}{ Alongamento } \\
\hline \multicolumn{3}{|c|}{$766 \mathrm{MPa}$} & \multicolumn{3}{|c|}{$852 \mathrm{MPa}$} & \multicolumn{3}{|c|}{$11 \%$} \\
\hline
\end{tabular}




\subsection{Procedimento de soldagem}

Os perfis tubulares quadrados foram soldados na posição plana, através do processo MAG automático com gás de proteção argônio $+\mathrm{CO}_{2}(25 \%)$ e vazão de $15 \mathrm{l} / \mathrm{min}$. Todos os cordões de solda foram realizados com ângulos de trabalho e deslocamento de $0^{\circ}$ e a distância bico de contato-peça de $20 \mathrm{~mm}$. As soldas foram depositadas em todo o contorno do perfil quadrado formando um conjunto soldado " $T$ ", conforme ilustrado na Figura 1a. As soldas foram denominadas considerando-se aquelas posicionadas transversalmente e longitudinalmente em relação à direção de aplicação da carga. Macrofotografias típicas das juntas soldadas estão mostradas nas Figura 1b, c.
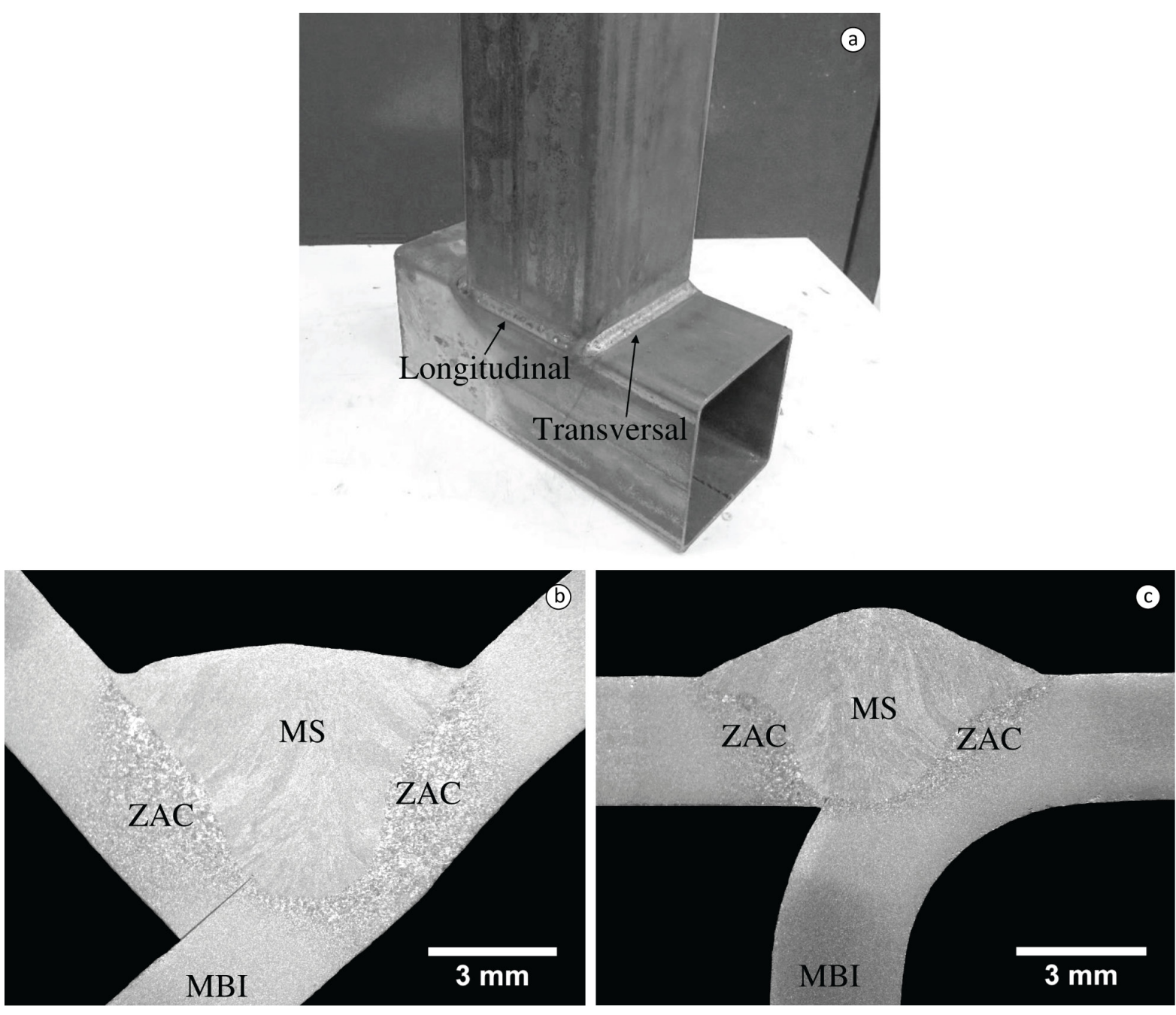

Figura 1. Juntas soldadas na posição plana: (a) Conjunto soldado em todo o contorno; (b) Junta transversal; (c) Junta longitudinal.

As soldas foram realizadas com os arames maciços AWS ER80S-G e AWS ER120S-G, ambos com diâmetro $1,2 \mathrm{~mm}$ e empregados individualmente. O primeiro consumível é definido como "undermatching" por apresentar resistência mecânica menor que o MB, e o segundo é "overmatching" por apresentar resistência mecânica maior que o MB [13,14]. A Tabela 2 apresenta as propriedades mecânicas dos metais de adição utilizados, segundo indicação do fabricante [15] e da AWS D1.1 [16].

Seis diferentes energias de soldagem foram produzidas através da variação da velocidade de soldagem, tensão e corrente. A Tabela 3 apresenta os parâmetros de soldagem utilizados. 
Efeitos da Energia de Soldagem e Consumível sobre a Resistência à Flexão Simples de Juntas Soldadas em Perfis Tubulares de Aço TMCP

Tabela 2. Propriedades mecânicas dos metais de adição (valores mínimos).

\begin{tabular}{ccccccc}
\hline $\begin{array}{c}\text { Metal de } \\
\text { Adição }\end{array}$ & \multicolumn{2}{c}{$\begin{array}{c}\text { Limite de Escoamento } \\
\text { (MPa) }\end{array}$} & Limite de Resistência à Tração & \multicolumn{2}{c}{$\begin{array}{c}\text { Alongamento } \\
(\mathbf{M P a})\end{array}$} \\
& Fabricante & AWS & Fabricante & AWS & Fabricante & AWS \\
AWS ER120S-G & 810 & $*$ & 900 & 830 & 18 & $*$ \\
AWS ER80S-G & 540 & $* 25$ & 550 & 26 & $*$ \\
\hline
\end{tabular}

* Não é especificado; deve ser estabelecido entre o comprador e o fornecedor.

Tabela 3. Parâmetros empregados para a realização dos cordões de solda.

\begin{tabular}{|c|c|c|c|c|c|c|}
\hline Condição & Experimento & $\begin{array}{c}\text { Tensão } \\
\text { Média (V) }\end{array}$ & $\begin{array}{l}\text { Corrente } \\
\text { Média (A) }\end{array}$ & $\begin{array}{l}\text { Velocidade } \\
\text { de Soldagem } \\
(\mathrm{mm} / \mathrm{s})\end{array}$ & $\begin{array}{c}\text { Energia de } \\
\text { Soldagem } \\
(\mathrm{kJ} / \mathrm{mm})\end{array}$ & $\begin{array}{c}\text { Velocidade de } \\
\text { Alimentação } \\
\text { do Arame } \\
\text { (m/mim) }\end{array}$ \\
\hline \multirow{6}{*}{$\begin{array}{c}\text { Solda } \\
\text { Longitudinal* }^{*}\end{array}$} & E1/120 & 22,5 & 139 & 9,2 & 0,3 & \multirow{3}{*}{4,0} \\
\hline & $E 2 / 120$ & 22,2 & 142 & 5,0 & 0,6 & \\
\hline & $\mathrm{E} 3 / 120$ & 22 & 145 & 3,5 & 0,9 & \\
\hline & $\mathrm{E} 4 / 120$ & 22,1 & 136 & 2,5 & 1,2 & 3,7 \\
\hline & $\mathrm{E} 4 / 120$ & 22,1 & 129 & 2,0 & 1,4 & 3,5 \\
\hline & $\mathrm{E} 6 / 120$ & 22,4 & 113 & 1,5 & 1,6 & 3,2 \\
\hline \multirow{6}{*}{$\begin{array}{c}\text { Solda } \\
\text { Transversal* }\end{array}$} & $E 7 / 80$ & 21,9 & 141 & 9,2 & 0,3 & \multirow{3}{*}{4,0} \\
\hline & $\mathrm{E} 8 / 80$ & 22,2 & 148 & 5,0 & 0,6 & \\
\hline & $\mathrm{E} 9 / 80$ & 21,9 & 150 & 3,5 & 0,9 & \\
\hline & E10/80 & 22,1 & 139 & 2,5 & 1,2 & 3,7 \\
\hline & E11/80 & 22,1 & 134 & 2,0 & 1,4 & 3,5 \\
\hline & E12/80 & 22,4 & 112 & 1,5 & 1,6 & 3,2 \\
\hline
\end{tabular}

* Denominações em relação à direção de aplicação da carga. Todas as soldas foram produzidas na posição plana.

\subsection{Caracterização das juntas soldadas}

Três amostras da seção transversal da junta soldada de cada condição (tipo de junta e energia de soldagem) apresentada na Tabela 3 foram seccionadas para a realização de ensaios metalográficos, seguindo a norma ASTM E3-95 [17]. Os corpos de prova foram abundantemente refrigerados e cortados com um disco. Todas as amostras foram embutidas a frio com resina acrílica, e as superfícies foram preparadas com lixas d'água de granulometria (80 a 1200 mesh), alternando o sentido em $90^{\circ}$ em cada etapa do lixamento.

Após o lixamento, as peças foram atacadas com Nital 2\%, em tempos de aproximadamente 15 segundos. Em seguida, as amostras foram lavadas em água corrente e secadas. As macrofotografias das juntas foram registradas com uma lupa (microscópio de baixo aumento), e a geometria das juntas (área total do MS; área total da região de crescimento de grão (RCG) da ZAC; largura máxima do MS; largura máxima da RCG da ZAC; garganta; área do MS sem reforço) foram medidas com o software "Image J". A garganta das juntas foi medida conforme o procedimento indicado nas Figura 2a, b. Em seguida, estes valores foram utilizados para determinar a área da seção resistente das juntas soldadas (garganta $\times$ comprimento da solda).

Posteriormente utilizando as mesmas amostras, foram realizados os perfis de microdureza Vickers nas juntas soldadas longitudinais com carga de 500 gf durante 10 segundos, seguindo recomendações da norma ASTM E384-11 [18]. As deduções das diferentes regiões da junta foram identificadas através das macrofotografias e dos perfis de microdureza. Na Figura 3 encontra-se esquematicamente o trajeto sobre o qual as microdurezas foram medidas através do MS, ZAC e metal base inalterado (MBI).

\subsection{Flexão simples}

O comportamento das juntas soldadas quando submetido a esforços de flexão foi avaliado através do auxílio de uma bancada. Esta foi equipada com um sistema hidráulico automatizado para a transmissão de esforços e um pórtico em perfil rígido de aço soldado para fixação das estruturas a serem ensaiadas. Para garantir a rigidez da 

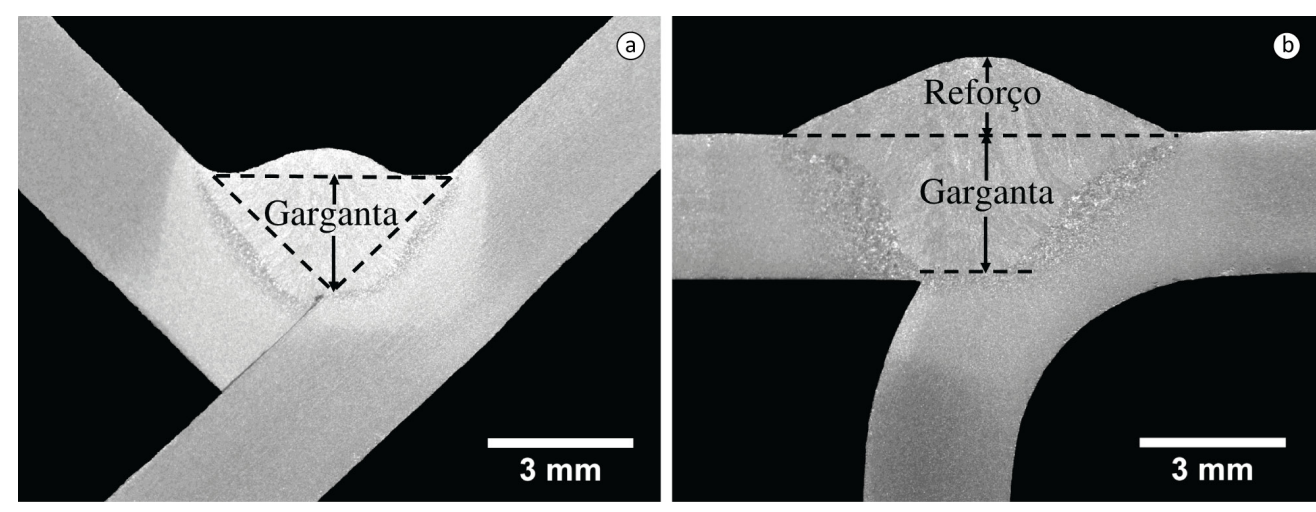

Figura 2. Esquemática da medição da garganta: (a) Junta transversal; (b) Junta longitudinal.

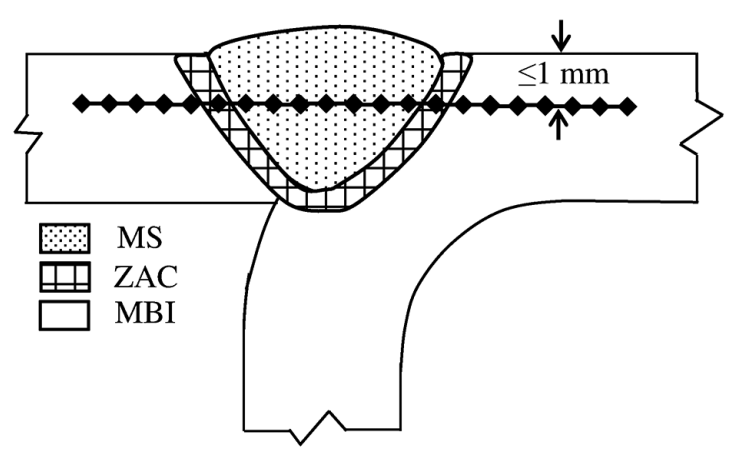

Figura 3. Desenho esquemático da linha onde foram realizados os perfis de microdureza.

estrutura, a coluna foi biengastada, ou seja, fixada nas duas extremidades. Entretanto, para transmitir a carga na estrutura foi montado e soldado um suporte na viga.

Também faz parte desta bancada um sistema de aquisição de dados, que recebe as informações provenientes dos extensômetros, transdutor de deslocamento linear (LVDT) e da célula de carga, e as envia para um computador. Os dados das deformações da célula de carga são recebidos pelo sistema de aquisição em uma ponte completa de Wheatstone. As medições do deslocamento vertical do pistão do cilindro hidráulico foram realizadas com o LVDT, utilizando a configuração de $1 / 2$ ponte de Wheatstone. No sistema montado, as deformações específicas da estrutura foram medidas por extensômetros com configuração $1 / 4$ de ponte de Wheatstone e ligados com três fios. As deformações específicas da estrutura durante o ensaio de flexão, foram medidas por extensômetros uniaxiais e triaxiais fixados na viga, distantes $30 \mathrm{~mm}$ da coluna, ou $530 \mathrm{~mm}$ do ponto de aplicação da carga.

Em relação ao ensaio de flexão, a velocidade de deformação da estrutura, ou seja, a velocidade de carregamento foi mantida em $0,2 \mathrm{~mm} / \mathrm{s}$ e as medições do ensaio foi encerrada após a ruptura da estrutura. A Figura 4 a mostra um conjunto soldado sendo submetido à flexão simples e a Figura 4b ilustra esquematicamente as dimensões do conjunto soldado, assim como o ponto de carregamento, e local de posicionamento dos extensômetros e do LVDT.

Então, no plano superior da viga são adquiridas as deformações específicas $\left(\varepsilon_{x}\right)$ através do extensômetro uniaxial, e as tensões normais são calculadas pela fórmula de Hooke $\left(\sigma_{x}=E . \varepsilon_{x}\right)$. Obtém-se a tensão/deformação de cisalhamento através das Equações (1 e 2), a partir das deformações medidas pelos extensômetros triaxiais que estão no plano lateral da viga, conforme apresentado na Figura $4 b$, sendo $\varepsilon_{a}$ na direção longitudinal da viga, ou "X", $\varepsilon_{\mathrm{c}}$ a $90^{\circ}$, ou "Y", e $\varepsilon_{\mathrm{b}}$ a $45^{\circ}[19,20]$.

$$
\begin{aligned}
& \tau_{1,2}=\frac{E}{2}\left[\left(\frac{\varepsilon_{A}+\varepsilon_{C}}{1-v}\right) \pm \frac{1}{1+v} \sqrt{\left(\varepsilon_{A}-\varepsilon_{C}\right)^{2}+\left(2 \varepsilon_{B}-\varepsilon_{A}-\varepsilon_{C}\right)^{2}}\right] \\
& \varepsilon_{1,2}=\left(\frac{\varepsilon_{A}+\varepsilon_{C}}{2}\right) \pm \frac{1}{2} \sqrt{\left(\varepsilon_{A}-\varepsilon_{C}\right)^{2}+\left(2 \varepsilon_{B}-\varepsilon_{A}-\varepsilon_{C}\right)^{2}}
\end{aligned}
$$


Efeitos da Energia de Soldagem e Consumível sobre a Resistência à Flexão Simples de Juntas Soldadas em Perfis Tubulares de Aço TMCP
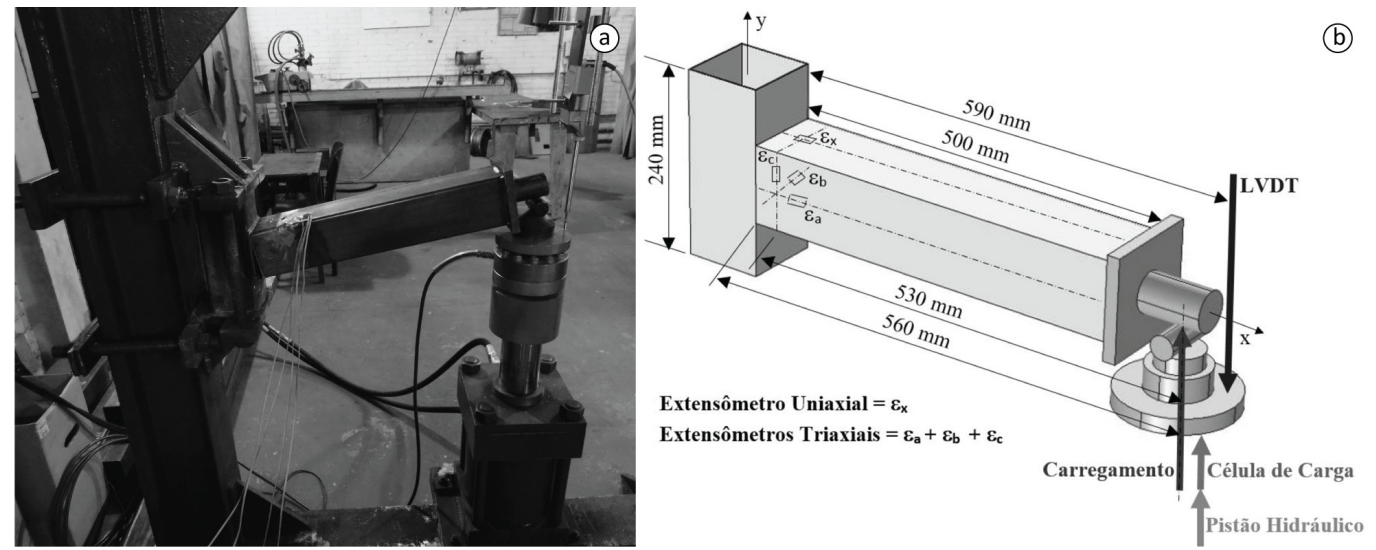

Figura 4. (a) Conjunto montado no pórtico de fixação, sendo submetido à flexão simples; (b) Desenho esquemático do ensaio de flexão simples.

\section{Resultados e Discussão}

\subsection{Microdureza e geometria das juntas soldadas}

Os perfis de microdureza transversais aos cordões de solda foram realizados nas juntas soldadas longitudinalmente, com diferentes energias de soldagem e metais de adição AWS ER80S-G e AWS ER120S-G. As Figura 5a-f apresentam os perfis de microdureza do MBI, da ZAC e do MS, em função da distância da linha central do cordão de solda.
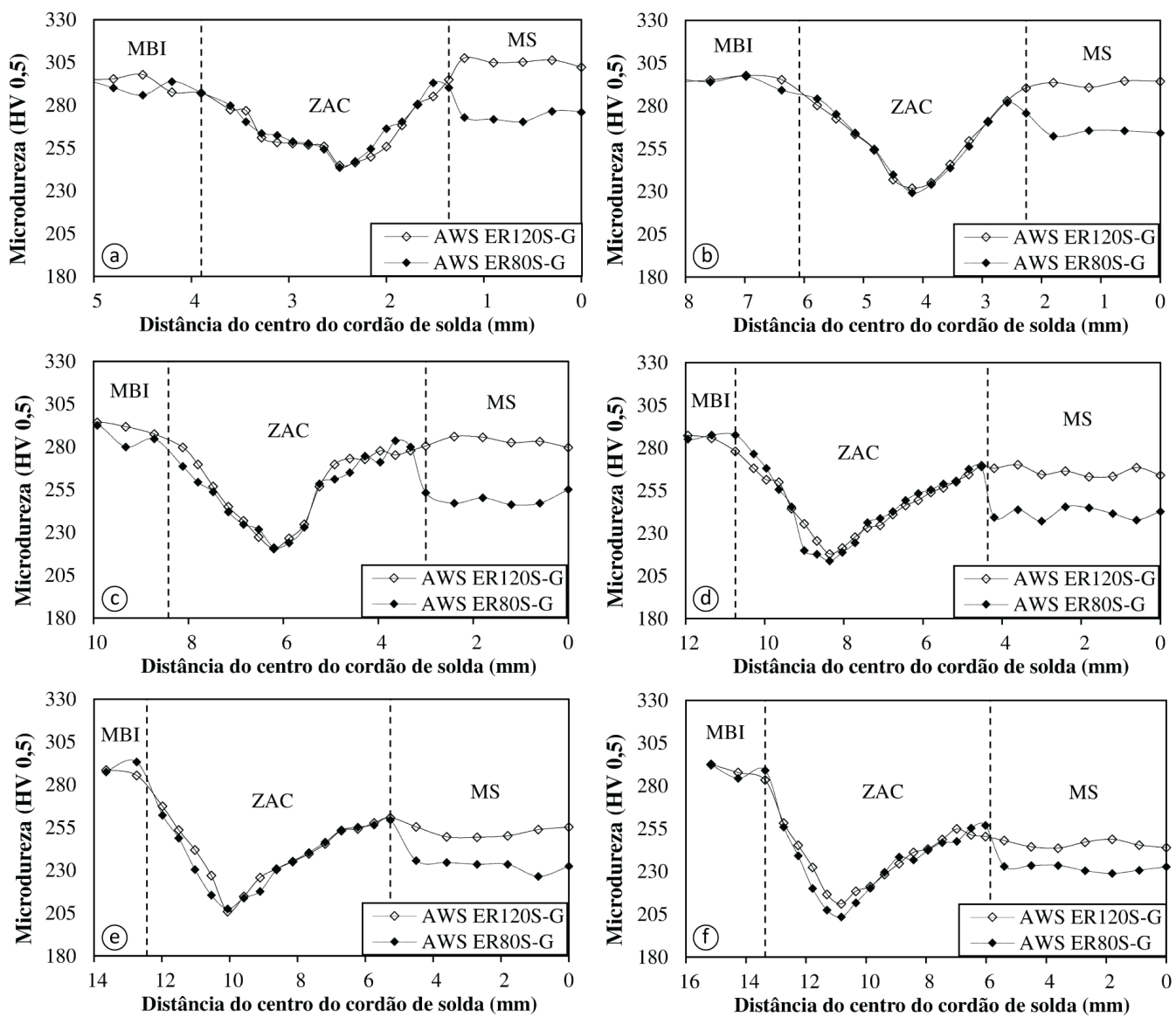

Figura 5. Perfis de microdureza das juntas longitudinais soldadas com diferentes energias de soldagem: (a) $0,3 \mathrm{~kJ} / \mathrm{mm}$; (b) $0,6 \mathrm{~kJ} / \mathrm{mm}$; (c) $0,9 \mathrm{~kJ} / \mathrm{mm}$; (d) $1,2 \mathrm{~kJ} / \mathrm{mm}$; (e) $1,4 \mathrm{~kJ} / \mathrm{mm}$; (f) $1,6 \mathrm{~kJ} / \mathrm{mm}$. 
A ZAC identificada pelo perfil de microdureza nas Figura $5 a-f$ são resultantes de alterações microestruturais do $\mathrm{MB}$ associado aos ciclos térmicos durante a soldagem. Portanto apresentam microestruturas diferentes entre si, além de microdurezas e propriedades mecânicas distintas [9]. Observa-se nessas figuras uma acentuada queda de dureza na ZAC em relação ao MBI. Outro fato evidente é a existência de um gradiente de microdureza na ZAC; esse fenômeno é consequência do gradiente de temperaturas desenvolvido durante a soldagem [21]. Então, provavelmente o fator principal para a redução de dureza na ZAC e do MS foi o aumento da energia de soldagem, tal como nos resultados apresentados por [9,11,22]. Além disso, para uma mesma energia de soldagem, o MS do consumível AWS ER120S-G sempre exibiu maior dureza que o do arame AWS ER80S-G.

A relação da energia de soldagem com a área total da RCG da ZAC e do MS é exibida nas Figura 6a, b. Conforme mostrado nessas figuras, o acréscimo na energia de soldagem contribuiu muito para o aumento da área do MS, e consequentemente, para a ampliação da RCG da ZAC [9]. Além disso, a área do MS sempre foi maior que a área da RCG da ZAC, independentemente do metal de adição e do tipo de junta. As áreas das ZACs das juntas transversais soldadas com energias de soldagem superiores a $0,6 \mathrm{~kJ} / \mathrm{mm}$ foram maiores, quando comparadas às juntas longitudinais e isso provavelmente se deve às diferenças geométricas entre elas.
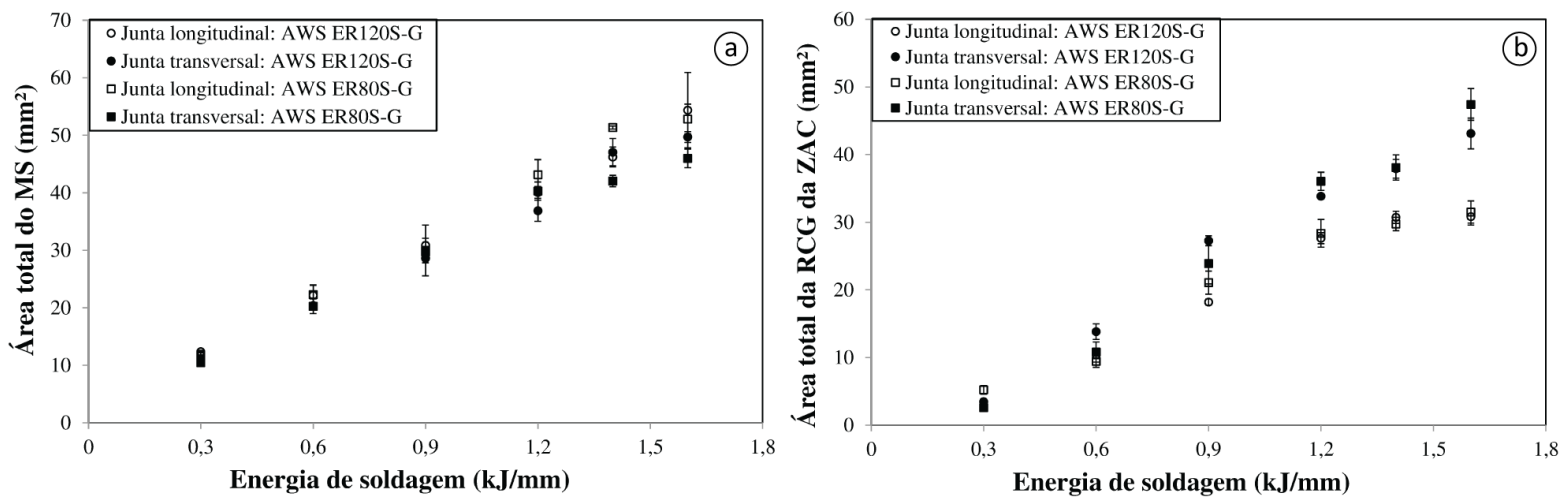

Figura 6. Energia de soldagem versus: (a) Área total do MS; (b) Área total da RCG da ZAC.

As Figura 7a, b mostram a largura máxima do MS e da RCG da ZAC em função da energia de soldagem. Neste caso, a largura máxima do MS e da RCG da ZAC aumentaram gradativamente com a elevação da energia de soldagem. Além disso, a largura máxima do MS e da RCG da ZAC das juntas longitudinais sempre foram maiores, quando comparado às juntas transversais. A largura máxima da RCG da ZAC aumentou gradativamente desde a energia de soldagem mínima até $0,9 \mathrm{~kJ} / \mathrm{mm}$; a partir deste valor, a RCG praticamente não sofreu significativa alteração.
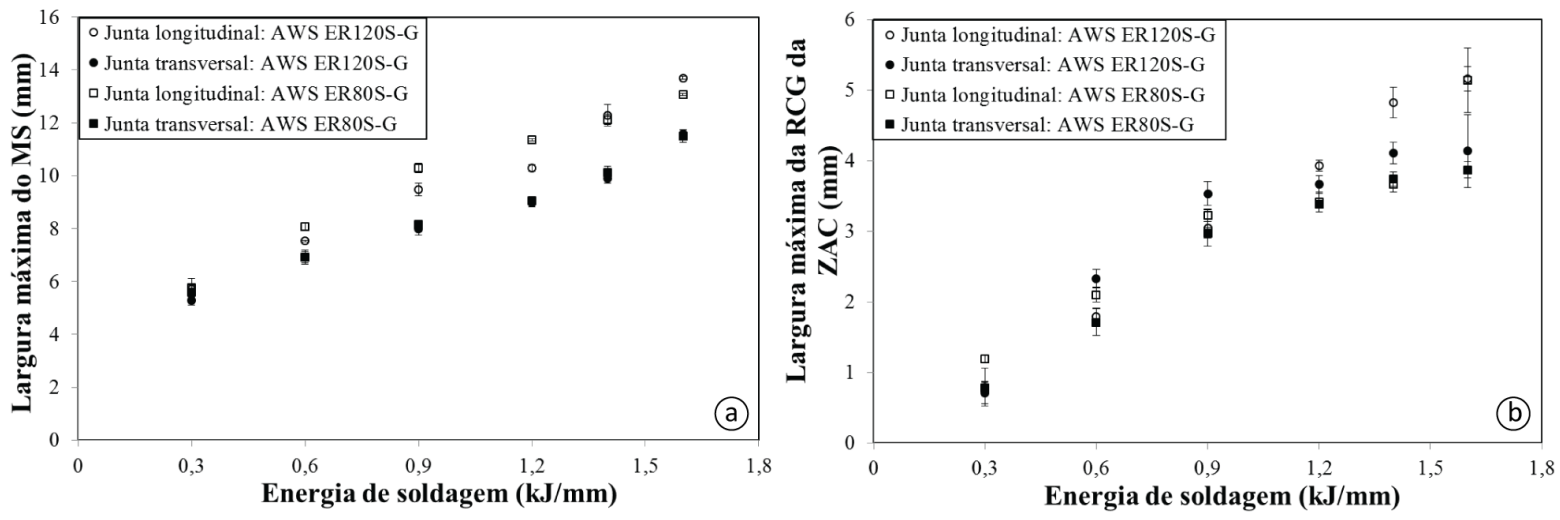

Figura 7. Energia de soldagem versus: (a) Largura máxima do MS; (b) Largura máxima da RCG da ZAC. 
Efeitos da Energia de Soldagem e Consumível sobre a Resistência à Flexão Simples de Juntas Soldadas em Perfis Tubulares de Aço TMCP

Observa-se nas Figuras 6a, b e 7a, b uma queda de declividade gradual dos pontos inicias em relação aos finais. Uma das causas deste comportamento está relacionada ao aumento da energia de soldagem, devido à redução da velocidade de soldagem [21,23] e sabe-se [22] que quanto maior a velocidade de soldagem, mais elevado é o rendimento térmico, talvez justificando a variação da área/largura do MS e da RCG da ZAC entre a energia de soldagem mínima e a máxima.

As relações da energia de soldagem com a área do MS (sem reforço) e a garganta estão nas Figura 8a, b. A Figura 8a mostra que a garganta das juntas transversais aumentou consideravelmente (de 0,3 a 1,4 kJ/mm) e diminuiu nas condições onde foi empregado $1,6 \mathrm{~kJ} / \mathrm{mm}$; somente as juntas longitudinais soldadas com 0,3 kJ/mm não apresentaram penetração completa. Todas as juntas longitudinais com energias de soldagem mais elevadas apresentaram penetração completa ou excesso de penetração, então, nesses casos a garganta é igual a espessura da chapa. Contudo, a área do MS sem o reforço caiu drasticamente com o uso de energias de soldagem mais elevadas, principalmente nas juntas longitudinais, conforme ilustrado na Figura 8b.
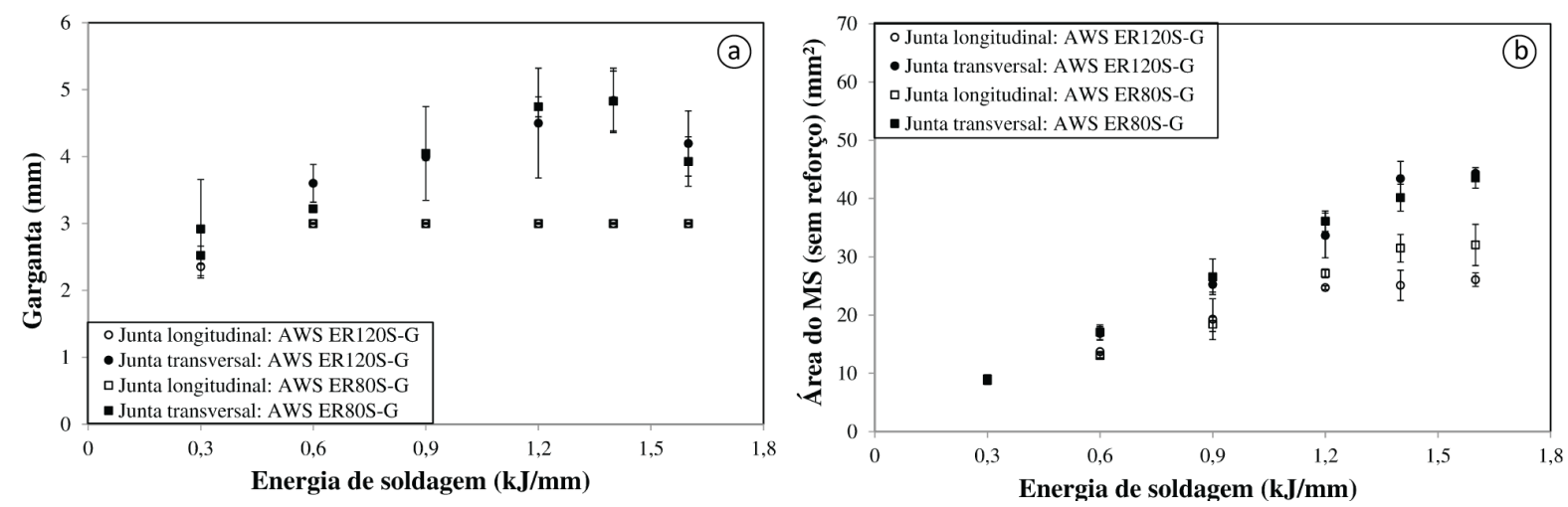

Figura 8. Efeito da energia de soldagem sobre: (a) Garganta da solda; (b) Área do MS (sem o reforço).

As medidas apresentadas neste subitem devem ser levadas em consideração, justamente pelo fato destas interferir diretamente com a resistência à flexão das juntas soldadas. Como pode ser observado, o acréscimo da área/largura do MS contribuiu para o aumento da resistência à flexão das juntas soldadas, somente enquanto a área da seção resistente aumenta. A partir de determinado momento, a área da seção resistente não aumenta com a ampliação da energia de soldagem. O que acontece é apenas uma redução de microdureza e um incremento na área/largura da ZAC. Em função destes fatores a integridade estrutural das juntas soldadas pode ser prejudicada quando for utilizado energias de soldagem muito elevadas, pois o "efeito entalhe" promovido nas regiões de menor dureza é mais elevado e a probabilidade de ocorrer falhas nesta região aumenta.

\subsection{Resistência das juntas soldadas à flexão simples}

Em geral, o alongamento de um membro diminui na medida em que a resistência ao escoamento do aço que o compõe aumenta [10]; porém a resistência estática de juntas soldadas depende das propriedades do MS, ZAC e MB [24]. Em função destes fatores, não basta de forma alguma os metais de solda e base atenderem os níveis de tenacidade e ductilidade requeridos por diversas normas [25] e Códigos [16], pois estes resultados não representam adequadamente as situações reais pelas quais passam as mais diversas estruturas soldadas. Dessa forma, os projetistas e engenheiros de soldagem devem atentar para alguns importantes fatos relativos à ductilidade da junta soldada, e projetos com excessiva rigidez devem ser evitados para reduzir a ocorrência de falhas [26].

A integridade (estrutural) não depende somente das propriedades mecânicas individuais dos membros que compõem a estrutura, mas é consequência de diversos outros fatores, inclusive do tipo do carregamento e do estado de tensões [26]. As concentrações de tensões produzidas pelas juntas soldadas reduzem a resistência em carregamento estático e diminuem muito a resistência a fadiga dos membros que conectam, assim como a intensidade da carga de impacto que suportam [27]. As Figura 9a-d mostram fotografias e macrofotografias típicas das juntas soldadas longitudinalmente e transversalmente, em relação à aplicação da carga. 

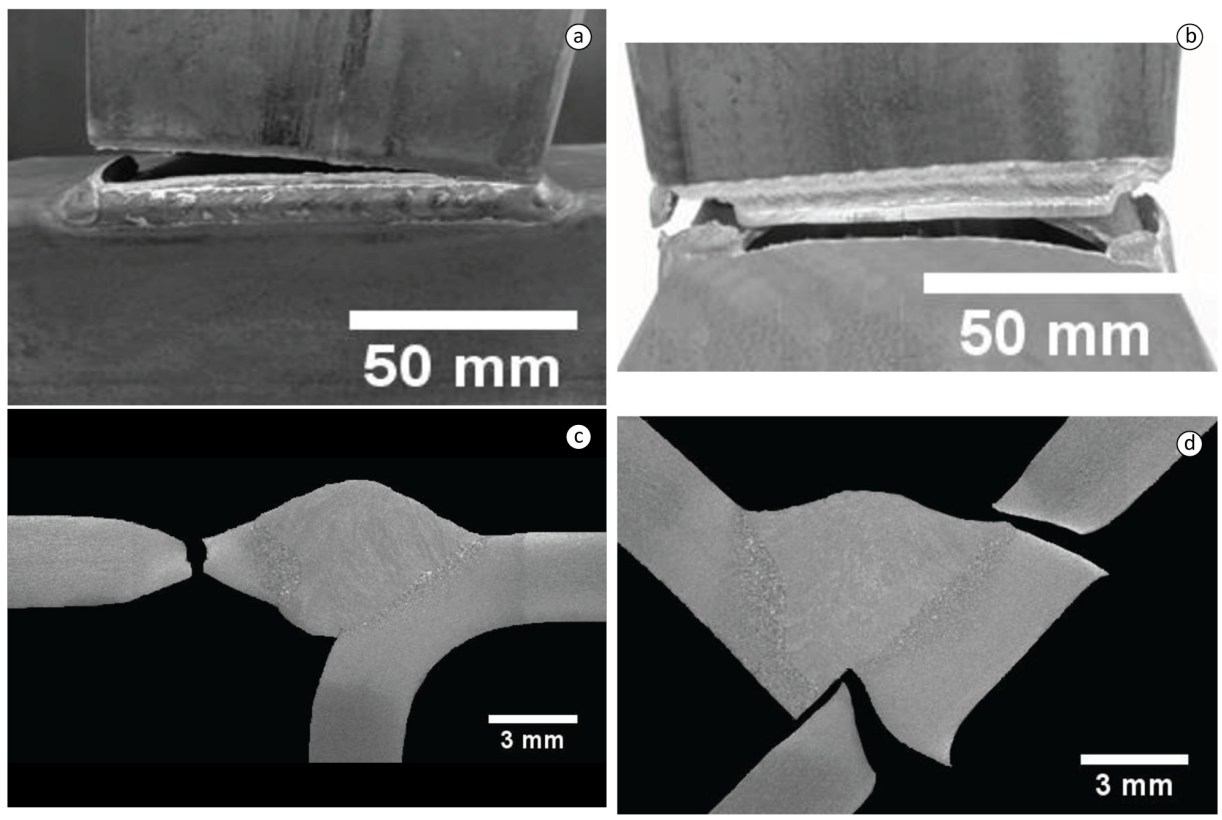

Figura 9. Juntas fraturadas por flexão simples: (a, c) Junta longitudinal soldada com 0,9 kJ/mm; (b, d) Junta transversal soldada com $0,6 \mathrm{~kJ} / \mathrm{mm}$.

Todos os corpos de prova das juntas soldadas fraturaram na ZAC de forma dúctil, pois houve significativa redução da seção transversal. Conforme mostrado nestas figuras, as juntas soldadas longitudinais apresentaram fraturas com características distintas das juntas transversais, em função do modo de carregamento, porém, para o mesmo tipo de junta às fraturas apresentam certa tendência de ocorrer numa mesma região relativa, independentemente da energia de soldagem utilizada. As fraturas das juntas longitudinais localizaram-se na ZAC, justamente na região de menor dureza. Por sua vez, as fraturas das juntas transversais, ocorreram ao longo da raiz e da margem da solda, provavelmente devido a concentração de tensão ser mais elevada nestas regiões.

A Tabela 4 apresenta as forças máximas suportadas pelas estruturas e as deformações medidas, bem como as resultantes tensões normal e de cisalhamento nos perfis retangulares tubulares em seus planos superior e lateral esquerdo, para diferentes energias de soldagem e consumíveis. Além disto, nesta tabela também se encontram as

Tabela 4. Forças máximas suportadas pelas estruturas e deformações medidas, com resultantes tensões de cisalhamento e normal.

\begin{tabular}{cccccccc}
\hline Experimento & $\begin{array}{c}\text { Energia de } \\
\text { Soldagem } \\
(\mathbf{k J / m m})\end{array}$ & $\begin{array}{c}\text { Área Média } \\
\text { da Seção } \\
\text { Resistente } \\
\left(\mathbf{m m}^{2}\right)\end{array}$ & $\begin{array}{c}\text { Força máxima } \\
\text { suportada } \\
\text { pela estrutura } \\
\mathbf{( k N )}\end{array}$ & $\begin{array}{c}\text { Cisalhamento (máx.) } \\
\text { Tensão } \\
(\mathbf{M P a})\end{array}$ & $\begin{array}{c}\text { Deformação } \\
(\mathbf{m m} / \mathbf{m m})\end{array}$ & $\begin{array}{c}\text { Tensão } \\
(\mathbf{M P a})\end{array}$ & $\begin{array}{c}\text { * Normal (máx.) } \\
\text { Deformação } \\
(\mathbf{m m} / \mathbf{m m})\end{array}$ \\
\hline E1/120 & 0,3 & 1055 & 32,1 & 194,3 & 0,0008 & $-588,3$ & $-0,0028$ \\
E2/120 & 0,6 & 1320 & 38,3 & 266,7 & 0,00116 & $-636,4$ & $-0,003$ \\
E3/120 & 0,9 & 1399 & 40,4 & 363,9 & 0,00161 & $-935,6$ & $-0,0045$ \\
E4/120 & 1,2 & 1500 & 42,0 & 485,1 & 0,00224 & $-1110,4$ & $-0,0053$ \\
E5/120 & 1,4 & 1568 & 41,5 & 389,5 & 0,00157 & $-1031,1$ & $-0,0049$ \\
E6/120 & 1,6 & 1439 & 38,9 & 308,1 & 0,00141 & $-850,2$ & $-0,004$ \\
E7/80 & 0,3 & 1088 & 27,7 & 285,9 & 0,00132 & $-532,2$ & $-0,0025$ \\
E8/80 & 0,6 & 1244 & 33,6 & 297,8 & 0,00127 & $-665,4$ & $-0,0032$ \\
E9/80 & 0,9 & 1409 & 33,8 & 319,9 & 0,00148 & $-726,0$ & $-0,0035$ \\
E10/80 & 1,2 & 1549 & 40,7 & 422,1 & 0,00194 & $-838,5$ & $-0,004$ \\
E11/80 & 1,4 & 1566 & 39,4 & 351,4 & 0,00165 & $-838,1$ & $-0,004$ \\
E12/80 & 1,6 & 1385 & 38,1 & 329,5 & 0,00149 & $-774,4$ & $-0,0037$ \\
\hline
\end{tabular}

* A tensão/deformação normal é negativa em função do extensômetro uniaxial estar submetido à esforços de compressão. 
Efeitos da Energia de Soldagem e Consumível sobre a Resistência à Flexão Simples de Juntas Soldadas em Perfis Tubulares de Aço TMCP

áreas médias das seções resistentes [16] das juntas consideradas, ou seja, a adição dos produtos do comprimento de cada lado do perfil pela respectiva garganta da junta soldada. Os valores de deformação, força e tensão que serão apresentados, referem-se ao momento exato da ruptura, ou seja, no instante em que ocorreu a força máxima suportada pelas juntas soldadas. Este fato é facilmente constatado através dos registros da força durante o ensaio, pois ocorre súbita redução da força exercida sobre a célula de carga.

Conforme apresentado na Tabela 4, as juntas soldadas com ambos os metais de adição apresentam progressivo aumento da força última de ruptura, conforme aumenta a energia de soldagem até $1,2 \mathrm{~kJ} / \mathrm{mm}$. Com esta energia de soldagem, as resistências à flexão das juntas produzidas são $31,2 \%$ e 46,9\% maiores do que aquelas soldadas com 0,3 kJ/mm, empregando-se os consumíveis AWS ER120S-G e AWS ER80S-G, respectivamente. Também se infere desta tabela que: (a) energias de soldagem superiores a $1,2 \mathrm{~kJ} / \mathrm{mm}$ aparentemente não são eficazes para aumentar a resistência à flexão das juntas em questão; (b) apesar do consumível AWS ER120S-G possuir resistência à tração nominal 33,3\% maior do que o AWS ER80S-G, nesta situaçã̃o específica a diferença entre a força última de ruptura é de somente $3,5 \%$.

Por outro lado, através da teoria elementar de resistência dos materiais, é possível calcular teoricamente as tensões normais ( $\sigma=M . c / I$ ) e de cisalhamento $[\tau=V . Q /(I .2 t)]$ em vigas de seção quadrada vazada, onde " $M$ " é o momento, "c" a distância da linha neutra à posição considerada, "I" o momento de inércia, " $V$ " a força cortante, " $Q$ " o momento estático em relação à linha neutra da parte da seção transversal da viga localizada acima da posição considerada e " $\mathrm{t}$ " a espessura da parede do tubo nesta seção [19,20]. Empregando-se as equações elementares de resistência dos materiais acima descritas, verifica-se que predomina o momento e não a tensão de cisalhamento. Inclusive, analisando-se a Tabela 4 nota-se que as tensões normais são muito superiores às tensões de cisalhamento.

\section{Conclusão}

Através dos resultados apresentados neste trabalho e estritamente no seu âmbito, as seguintes conclusões podem ser retiradas:

(1) A soldagem MAG de perfis tubulares quadrados do aço DOMEX $700 \mathrm{MC}^{\mathrm{TM}}$ com espessura de $3 \mathrm{~mm}$ é viável, porém na situação investigada, a integridade estrutural das juntas soldadas pode ser prejudicada quando for utilizado energias de soldagem muito elevadas, pois o "efeito entalhe" promovido nas regiões de menor dureza é mais elevado e a probabilidade de ocorrer falhas nesta região aumenta.

(2) A energia de soldagem é o fator predominante na resistência à flexão das estruturas soldadas nesta investigação, porém somente enquanto aumenta significativamente a área da seção resistente da junta soldada (produto da garganta pelo comprimento da solda). Isso é corroborado pelo fato das juntas soldadas com os consumíveis AWS ER120S-G e AWS ER80S-G apresentarem progressivo aumento da resistência à flexão com a elevação da energia de soldagem, até o limite de $1,2 \mathrm{~kJ} / \mathrm{mm}$.

(3) Energias de soldagem superiores a 1,2 kJ/mm não são eficazes para aumentar a resistência à flexão das juntas soldadas ora investigadas. A partir deste valor, o efeito da energia de soldagem sobre a redução da dureza e, consequentemente, resistência mecânica da ZAC, aparentemente se sobrepõe ao aumento da área da seção resistente da junta soldada.

(4) Juntas soldadas com mesma energia de soldagem apresentaram tendência a maior resistência à flexão com o consumível AWS ER120S-G do que com o AWS ER80S-G. Entretanto, apesar do primeiro consumível possuir resistência à tração nominal 33,3\% maior do que o segundo, na situação específica desta investigação a diferença entre a força última de ruptura é de somente 3,5\% a favor do AWS ER120S-G na ótima energia de soldagem $(1,2 \mathrm{~kJ} / \mathrm{mm})$, ou aquela na qual a estrutura apresentou maior resistência à flexão em ambos os casos.

\section{Agradecimentos}

Os autores agradecem à SSAB e especialmente ao Engo João Ricardo Boff Preichard, por ter fornecido o aço DOMEX 700 MC $^{\text {TM }}$ e ao LdTM (UFRGS) pelo empréstimo do sistema de aquisição de dados. O Mestrando RLD agradece ao CNPq (Brasil) por conceder a bolsa de estudos. 


\section{Referências}

[1] American Society for Metals. ASM Handbook: metalworking: bulk forming. Novelty: ASM International; 2005. v. 14A, 888 p.

[2] Bhadeshia HKDH, Honeycombe RWK. Steel: microstructure and properties. 3. ed. Cambridge: Elsevier; 2006. 344 p.

[3] Gladman T. The physical metallurgy of microalloyed steels. London: Institute of Materials; 1997. 363 p.

[4] Ghosh A, Das S, Chatterjee S, Mishra B, Rao PR. Influence of thermo-mechanical processing and different post-cooling techniques on structure and properties of an ultra low carbon $\mathrm{Cu}$ bearing HSLA forging. Materials Science and Engineering A. 2003;348(1-2):299-308. http://dx.doi.org/10.1016/S09215093(02)00735-9.

[5] Tamura I, Sekine H, Tanaka T, Ouchi C. Thermomechanical processing of high-strength low-alloy steels. Oxford: ButterworthHeinemann; 1988. 248 p.

[6] SSAB TUNNPLAT. Sheet steel joining handbook: joining of high strength steels. Sweden: SSAB Tunnplat AB; 2004.

[7] European Committee for Standardization. EN 10149-2: hot rolled flat products made of high yield strength steels for cold forming. Part 2: delivery conditions for thermomechanically rolled steels. Brussels: ECS; 1995.

[8] Kapustka N, Conrardy C, Babu S, Albrigth C. Effect of GMAW process and material conditions on DP 780 and TRIP 780 welds. Welding Research. Supplement to the Welding Journal. 2008;87:135-148.

[9] Hochhauser F, Ernst W, Rauch R, Vallant R, Enzinger N. Influence of the soft zone on the strength of welded modern HSLA steels. Welding in the World. 2012;56(5-6):77-85. http://dx.doi. org/10.1007/BF03321352.

[10] Pirinen M. The effects of welding heat input on the usability of high strength steels in welded structures [tese de doutorado]. Lappeenranta: Lappeenranta University of Technology; 2013.

[11] Górka J. Influence of the maximum temperature of the thermal cycle on the properties and structure of the HAZ of steel S700MC. IOSR Journal of Engineering. 2013;3(11):22-28. http://dx.doi. org/10.9790/3021-031142228.

[12] Associação Brasileira de Normas Técnicas. NBR ISO 6892: materiais metálicos: ensaio de tração à temperatura ambiente. Rio de Janeiro: ABNT; 2002.

[13] Miller DK. Welding of steel bridges: highway structures design handbook. Cleveland: The Lincoln Electric Company; 1994. 88 p.
[14] Machado IG. Novos paradigmas para especificação de juntas soldadas. Soldagem \& Inspeção. 2012;17(3):278-288. http:// dx.doi.org/10.1590/S0104-92242012000300012.

[15] ESAB. Catálogo de consumíveis [página da internet]. Contagem: ESAB; 2015 [acesso em 12 jan. 2015]. Disponível em: http:// www.esab.com.br/.

[16] American Welding Society. AWS D1.1: structural welding code: steel. Miami: AWS; 2006.

[17] American Society for Testing and Materials. ASTM E3-95: standard practice for preparation of metallographic specimens. West Conshohocken: ASTM; 1995.

[18] American Society for Testing and Materials. ASTM E384-11: standard test method for knoop and vickers hardness of materials. West Conshohocken: ASTM; 2011.

[19] Gere JM, Goodno BJ. Mechanics of materials. 7. ed. Canada: Cengage Learning, 2009; $1022 \mathrm{p}$.

[20] Beer FP, Johnston R Jr. Resistência dos materiais. 3. ed. São Paulo: Pearson Makron Books; 1995. 1255 p.

[21] Machado IG. Condução do calor na soldagem: fundamentos e aplicações. Porto Alegre: Imprensa Livre; 2000. 119 p.

[22] Rocha ICL, Machado IG, Mazzaferro CCP. Mechanical and metallurgical properties of DP 1000 steel square butt welded joints with GMAW. IACSIT International Journal of Engineering and Technology. 2015;4(1):26-34. http://dx.doi.org/10.14419/ ijet.v4i1.3928.

[23] Kou S. Welding metallurgy. 2. ed. Hoboken: John Wiley \& Sons; 2003. $461 \mathrm{p}$.

[24] Akbarnejad S. Investigation on static strength of welded joints [dissertação de mestrado]. Stockholm: Royal Institute of Technology; 2012. 124 p.

[25] American Institute of Steel Construction. Welded Connections: a primer for engineers. Chicago: AISC; 2006.

[26] Machado IG. Falhas de estruturas de aço soldadas devido a reduzida ductilidade. Soldagem \& Inspeção. 2013;18(4):391403. http://dx.doi.org/10.1590/s0104-92242013000400011.

[27] Machado IG. Dimensionamento de juntas soldadas de filete: uma revisão crítica. Soldagem \& Inspeção. 2011;16(2):189-201. http://dx.doi.org/10.1590/s0104-92242011000200011. 